\title{
Persistent Alterations in Mesolimbic Gene Expression with Abstinence from Cocaine Self-Administration
}

\author{
Willard M Freeman*, ${ }^{\prime, 2}$, Kruti M Patel ${ }^{1,2}$, Robert M Brucklacher², Malinda E Lull', Mandi Erwin', \\ Drake Morgan ${ }^{3}$, David CS Roberts ${ }^{4}$ and Kent E Vrana'
}

'Department of Pharmacology, Penn State College of Medicine, Hershey, PA, USA; ${ }^{2}$ Functional Genomics Facility, Penn State College of Medicine, Hershey, PA, USA; ${ }^{3}$ Department of Psychiatry, Division of Addiction Medicine, University of Florida College of Medicine, Gainesville, FL, USA;

${ }^{4}$ Department of Physiology and Pharmacology, Wake Forest University School of Medicine, Winston-Salem, NC, USA

\begin{abstract}
Cocaine-responsive gene expression changes have been described after either no drug abstinence or short periods of abstinence. Little data exist on the persistence of these changes after long-term abstinence. Previously, we reported that after discrete-trial cocaine selfadministration and 10 days of forced abstinence, incubation of cocaine reinforcement was observable by a progressive ratio schedule. The present study used rat discrete-trial cocaine self-administration and long-term forced abstinence to examine extinction responding, mRNA abundance of known cocaine-responsive genes, and chromatin remodeling. At 30 and 100 days of abstinence, extinction responding increased compared to 3-day abstinent rats. Decreases in both medial prefrontal cortex (mPFC) and nucleus accumbens cfos, Nr4al, Arc, and EGRI mRNA were observed, and in most cases persisted, for 100 days of abstinence. The signaling peptides CART and neuropeptide Y (NPY) transiently increased in the MPFC, but returned to baseline levels following 10 days of abstinence. To investigate a potential regulatory mechanism for these persistent mRNA changes, levels of histone $\mathrm{H} 3$ acetylation at promoters for genes with altered mRNA expression were examined. In the mPFC, histone $\mathrm{H} 3$ acetylation decreased after I and 10 days of abstinence at the promoter for EGRI. H3 acetylation increased for NPY after I day of abstinence and returned to control levels by 10 days of abstinence. Behaviorally, these results demonstrate incubation after discrete-trial cocaine self-administration and prolonged forced abstinence. This incubation is accompanied by changes in gene expression that persist long after cessation of drug administration and may be regulated by chromatin remodeling.

Neuropsychopharmacology (2008) 33, I807- |817; doi: 10.1038/sj.npp. I301577; published online 12 September 2007
\end{abstract}

Keywords: behavior; medial prefrontal cortex; nucleus accumbens; functional genomics; incubation; addiction

\section{INTRODUCTION}

Relapse to cocaine use after abstinence is a hallmark of cocaine addiction. Clinically, this is manifested in multiple relapse episodes with intervening periods of cocaine abstinence (O'Brien, 1996). Relapse liability - the likelihood that a cocaine-abstinent, formally cocaine-dependent individual will resume cocaine use - has been shown to be associated with a number of factors. Stress, environmental cues, and conditioned stimuli have all been demonstrated clinically to play roles in cocaine relapse (Wallace, 1989; O'Brien et al, 1998; Sinha, 2001). For treatment of cocaine addiction, relapse prevention presents the most promising point for intervention (O'Brien, 2005). Although initiating

\footnotetext{
*Correspondence: Dr WM Freeman, Department of Pharmacology, Penn State College of Medicine, H078, 500 University Drive, Hershey, PA, 17033, USA, Tel: + I 717531 4037, Fax: + I 717531 5013, E-mail:wfreeman@psu.edu

Received 21 May 2007; revised 15 August 2007; accepted I5 August 2007
}

drug abstinence can be accomplished through in-patient treatment, maintaining out-patient cocaine abstinence has proven difficult (Gossop et al, 2003) and prolonged cocaine abstinence is achieved by only a minority of patients (Bisaga et al, 2006; Rohsenow et al, 2000; Dackis et al, 2005). This may be due to increases in cocaine craving during abstinence (Gawin and Kleber, 1986). Understanding the persistent neurobiological changes that contribute to relapse liability would be an important step toward treatments that reduce the likelihood of cocaine relapse (Nestler, 2004).

To adequately model the neurobiological component of relapse liability, animal models need to demonstrate behavioral alterations that persist with cocaine abstinence. Work by Shaham, Hope, and colleagues has addressed this issue in a number of studies of incubation (reviewed in $\mathrm{Lu}$ et al, 2004; Shaham and Hope, 2005). In cocaine selfadministering rats, increased responding on the previously active lever was evident after 7 or more days of cocaine abstinence (Grimm et al, 2001). This phenomenon is incubation, and further studies demonstrated that persis- 
tent changes in mesolimbic (Lu et al, 2003) and amygdalar (Lu et al, 2005a) protein expression accompanied the behavioral change. This work suggests that long-lasting behavioral changes in drug-seeking and the underlying neurobiological alterations can be modeled in rodents.

We have developed a discrete-trial cocaine self-administration model that demonstrates an increase in the reinforcing efficacy of cocaine after prolonged forced abstinence (Morgan and Roberts, 2004; Morgan et al, 2005). Using access conditions in which cocaine was available for $24 \mathrm{~h} /$ day, but limited to four discrete trials an hour (DT4), increases in progressive ratio breakpoints were observed after 7 days of cocaine abstinence but not after 1 day of abstinence (Morgan et al, 2002, 2005). This increase in breakpoint was also dependent on the self-administration history, as cumulative dose-matched rats on a fixed ratio 1 (FR1) schedule did not display increased breakpoints (Morgan et al, 2005). We have described mRNA and protein expression changes that occur in the nucleus accumbens (NAc) and medial prefrontal cortex (mPFC) with this model (Marcellino et al, 2007; McCracken et al, 2005). The present study extended examination of the consequences (behavioral and molecular) of this self-administration history to 100 days of forced abstinence.

Mesolimbic structures such as the NAc and mPFC are of particular interest in long-lasting neurobiological alterations that may underlie relapse vulnerability. Human imaging studies have associated changes in the mPFC (Volkow et al, 2005; Childress et al, 1999) and NAc (Risinger et al, 2005) with cocaine craving. These reports are paralleled by rodent studies of relapse and reinstatement (for review, see Rebec and Sun, 2005; Kalivas and McFarland, 2003). At the molecular level, abstinence-induced or abstinence-persistent changes in mRNA and protein expression have been described in the MPFC and NAc after cocaine self-administration ( $\mathrm{Lu}$ et al, 2003; Sutton et al, 2003). Other brain structures, eg amygdala (Lu et al, 2007, 2005b) and ventral subiculum (Vorel et al, 2001; Taepavarapruk and Phillips, 2003), also play roles in reinstatement and will need to be examined in future studies.

The goal of this study was to further assess if the DT4 selfadministration schedule produced changes in extinction responding with forced abstinence and if molecular adaptations persist for as long as the behavioral changes. The set of transcripts examined, while not comprehensive, represent well-characterized gene alterations from several cocaine administration procedures. Specifically, the immediate early genes Fos (Graybiel et al, 1990), EGR1 (Daunais and McGinty, 1995), Arc (Fosnaugh et al, 1995), and Nr4a1 (Freeman et al, 2002b); neuropeptides CART (Douglass et al, 1995) and Neuropeptide Y (NPY; Westwood and Hanson, 1999); glutamate receptors (Carlezon and Nestler, 2002; Boudreau and Wolf, 2005), and homer genes (Szumlinski et al, 2006) were examined. Furthermore, for those genes that demonstrated persistent changes in mPFC mRNA abundance, histone $\mathrm{H} 3$ hyperacetylation was examined as a potential regulatory mechanism. Chromatin remodeling events have recently been described as accompanying psychomotor sensitization (Kumar et al, 2005). These studies suggest an interplay of gene expression and chromatin modifications that may serve to perpetuate molecular signals that can manifest themselves in persistently altered behavior.

\section{METHODS}

\section{Animals}

Male, Sprague-Dawley rats (Harlan Inc., IN) weighing approximately $300-400 \mathrm{~g}$ at the start of the experiments were used as subjects. Throughout these experiments, rats were maintained on a reverse light/dark cycle (lights on 1500 to 0300 hours) with food (Ralston Purina, St Louis, MO) and water available ad libitum. All research was approved by the Wake Forest University School of Medicine Animal Care and Use Committee and conducted according to the Guide for the Care and Use of Laboratory Animals, as promulgated by the National Institutes of Health.

\section{Surgery}

Following a 3- to 7-day acclimation period, rats were anesthetized with a ketamine $(100 \mathrm{mg} / \mathrm{kg}$, i.p.) and xylazine $(8 \mathrm{mg} / \mathrm{kg}$, i.p.) combination and implanted with a chronic indwelling silastic cannula (0.012 inch inner and 0.025 inch outer diameter) in the right jugular vein. Following surgery, rats received a single administration of butorphanol $(0.2 \mathrm{mg} / \mathrm{kg}$, s.c.) as an analgesic and $\sim 3 \mathrm{ml}$ (s.c.) of Lactated Ringer's solution to promote recovery. The cannula exited the skin on the dorsal surface of the scapulae region (Roberts and Goeders, 1989) went through a stainless steel protective spring tether, and was attached to a counterbalanced, fluid swivel mounted above the operant chamber allowing free movement within the chamber. Tygon tubing connected the swivel to an infusion pump (Razel Scientific Instruments Inc.) with a 5 r.p.m. motor. The operant chambers were $25 \times 25 \times 25 \mathrm{~cm}$ in size, and served as both housing and testing chambers.

Control rats were subjected to the same surgery as the cocaine self-administration rats with the same anesthesia and analgesia. Control animals were placed in identical operant chambers but without cannulas attached or infusions. Control rats remained in operant chambers for 10 days before removal and killing.

\section{Cocaine Self-Administration}

Three independent sets of rats were used in this study. The first (Group I; Figure 1) was examined for behavioral changes after varying periods of abstinence, the second and third (Groups II and III) were treated in the exact same manner, but not subjected to extinction responding. The second group was used for gene expression analysis and the third for chromatin remodeling experiments. Different rats were used for the behavioral and molecular analyses to avoid any molecular changes that could be caused by extinction testing (Figure 1). For the behavioral analysis $n=7-8$ per group; for gene expression studies $n=11$ for control rats, $n=6$ for 1-day abstinent rats, $n=7$ for 10 -day abstinent rats, and $n=8$ for 100-day abstinent rats; for chromatin remodeling $n=5$ per group. 


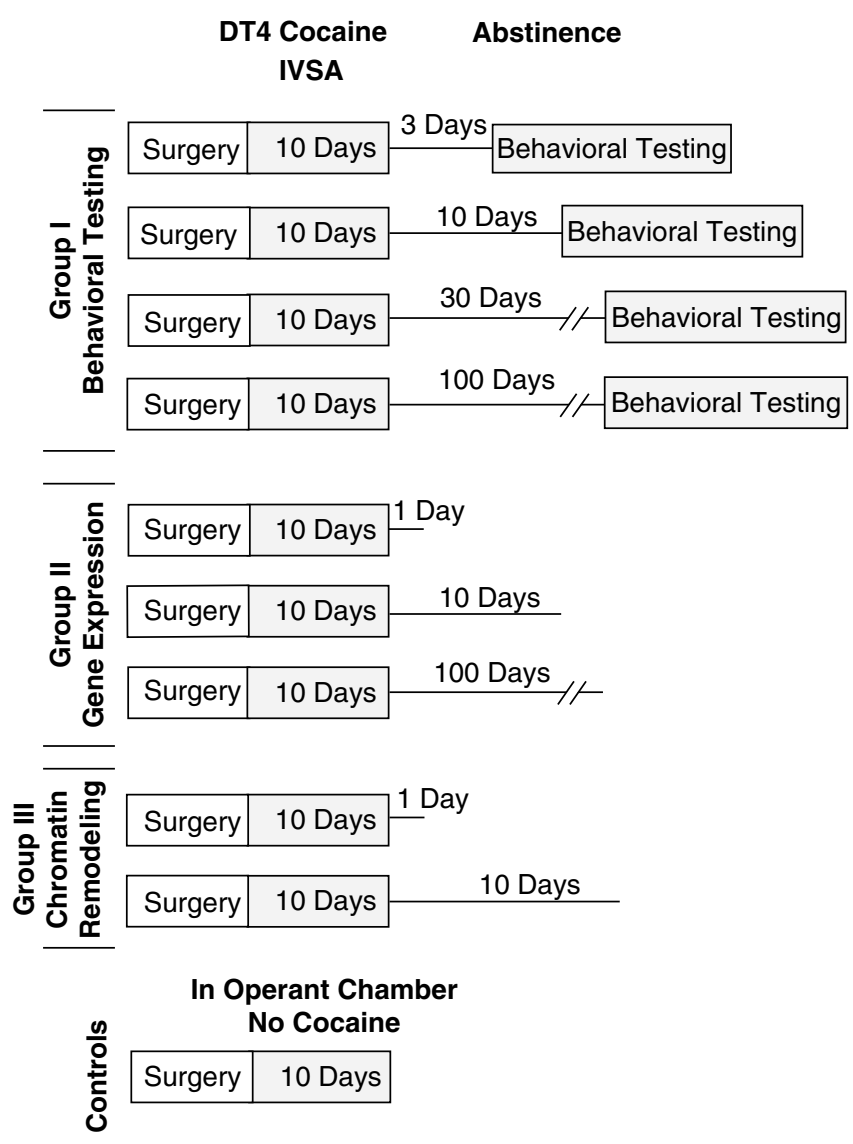

Figure I Schematic of the experimental groups used in behavioral testing, gene expression, and chromatin remodeling.

Training. Self-administration training began 1 day following surgery as previously described (Mateo et al, 2005; Ward et al, 2006). At the beginning of each daily session, a retractable lever extended into the cage to signal session onset. Completion of the response requirements resulted in the delivery of $1.5 \mathrm{mg} / \mathrm{kg}$ cocaine $(\sim 0.1 \mathrm{ml}$ of $5 \mathrm{mg} / \mathrm{ml}$ cocaine over $\sim 5 \mathrm{~s})$. Concurrent with the start of each injection, the lever retracted and a stimulus light was activated for $20 \mathrm{~s}$ to signal a time-out period. Levers were retracted, syringes were refilled, and any changes in schedule conditions were made $10 \mathrm{~min}$ before the start of each session. Rats were initially exposed to an FR1 schedule of reinforcement. Each training session lasted until 40 infusions had been self-administered, at which time the lever was retracted until the next daily session began.

Discrete-trial self-administration. After the rats had established a stable daily pattern of cocaine intake for at least 5 days (40 infusions within $6 \mathrm{~h}$, and no increasing or decreasing trends in time to finish session), the schedule conditions were changed to a discrete-trial schedule of reinforcement. During these sessions, rats were given access to cocaine during 10-min discrete trials. Trials were initiated at 15-min intervals with the introduction of a retractable lever into the chamber. A single response resulted in a cocaine infusion, which was signaled by the illumination of a stimulus light for $20 \mathrm{~s}$. A trial was terminated and the lever retracted if an injection $(1.5 \mathrm{mg} / \mathrm{kg}$ per injection) was collected or if $10 \mathrm{~min}$ had elapsed. Rats received four discrete trials per hour (ie DT4), $24 \mathrm{~h}$ per day for 10 days. These conditions have previously been employed and demonstrated to result in increased breakpoints after forced abstinence (Morgan et al, 2002, 2005).

Forced abstinence period. Following self-administration, rats were placed in standard polycarbonate cages for various durations of forced abstinence (spanning 1-100 days). Following this forced abstinence period, rats were tested in an extinction session, or were killed with the brain rapidly removed for the molecular biological analyses described below (see also Figure 1).

Extinction sessions. Following a particular duration of abstinence, rats in Group I were returned to the selfadministration chambers and connected to the tether system used to deliver drug. Catheters were flushed with saline, and the conditions associated with a typical self-administration session were reinstated (the lever was extended into the chamber and the houselights were illuminated). Following a response (on an FR1 schedule), the infusion pump was activated (delivering saline), the lever was retracted, and the stimulus lights over the lever were illuminated for $20 \mathrm{~s}$. These sessions were $2 \mathrm{~h}$ in duration.

\section{Drug Preparation}

Cocaine hydrochloride was obtained from the National Institute on Drug Abuse (Rockville, MD), dissolved in sterile $0.9 \%$ saline and passed through a microfilter, and the dosages are expressed as the salt.

\section{Dissection}

For molecular analysis, rats in Groups II and III (Figure 1) were killed following abstinence without extinction testing. Brains were rapidly removed, cooled in ice-chilled saline, and placed in an ice-chilled ASI brain slicer (ASI Instruments, Warren, MI). The section from bregma +4.2$2.2 \mathrm{~mm}$ (Paxinos and Watson, 2004) is cut along the forceps minor and the cortex medial of this cut is collected. This includes elements of the cingulate, prelimbic, medial orbital cortex, and frontal cortex. While the cortical dissection is specific, future studies will be needed to isolate individual elements. To date, precise cortical anatomy of these regions in the rat remains elusive as the dashed lines segmenting the cortical regions demonstrate. The section from +2.2$0.2 \mathrm{~mm}$ is cut $0.5 \mathrm{~mm}$ on each side of the midline, on a line connecting the tip of the external capsule and the previous cut, on a line connecting the tip of the external capsule and lateral ventricle, and between the ventricles. The NAc dissection includes core and shell.

\section{qRT-PCR}

Total RNA was isolated as described previously (Freeman et al, 2001a,b) using Tri Reagent (Molecular Research Center Inc., Cincinnati, OH) (Chomczynski and Mackey, 1995) from control rats and after 10 days of DT4 cocaine self-administration and 1, 10, or 100 days of abstinence. RNA quantity and quality were assessed using the Agilent 
2100 Bioanalyzer with the RNA 6000 Nano Assay (Agilent, Palo Alto, CA).

cDNA synthesis and qPCR were performed as previously described (Bowyer et al, 2007). qPCR on samples used the 7900HT Sequence Detection System (Applied Biosystems, Foster City, CA), 384-well optical plates, and Assay-OnDemand (Applied Biosystems) gene-specific primers and probes (Maley et al, 2004). A full listing of genes, gene names, and assay identification numbers is given in Supplementary Table 1 . Relative quantities were calculated using ABI SDS 2.2.2 RQ software and the $2^{-\Delta \Delta \mathrm{Ct}}$ analysis method (Bowyer et al, 2007; Livak and Schmittgen, 2001) with GAPDH as the endogenous control. GAPDH levels had been determined in preliminary absolute quantitation experiments to be unchanged with cocaine self-administration or forced abstinence (data not shown). Relative quantity values were normalized to give a mean of 1 for control rats to aid in comparison across genes with varying basal abundance.

\section{Chromatin Immunoprecipitation-PCR}

Chromatin immunoprecipitation (ChIP) experiments were performed similarly to those described previously by Nestler and colleagues (Kumar et al, 2005; Tsankova et al, 2004) and as directed by the manufacturer of the ChiP Assay Kit (Upstate Biotechnology, catalog no. 17-245). Briefly, fresh tissue samples from rat mPFC were incubated in $1 \%$ formaldehyde at room temperature for $15 \mathrm{~min}$, followed by incubation for 4-5 min at room temperature with an equal volume of $0.25 \mathrm{M}$ glycine. Liquid was removed and the tissue was washed five times with cold 1X PBS with protease inhibitors. Tissue was homogenized in lysis buffer $(10 \mathrm{mM}$ Tris, $10 \mathrm{mM} \mathrm{NaCl}, 0.2 \%$ Igepal 630) and centrifuged at $5 \mathrm{~kg}$ for $5 \mathrm{~min}$. The resulting pellet was used with the ChIP Assay Kit for K9 and 14-Histone H3 (Upstate Biotechnology) following the manufacturer's protocol with the following exceptions: (1) incubation times with the salmon sperm DNA/Protein A agarose slurry and the elution buffer were increased to $2 \mathrm{~h}$ and $25 \mathrm{~min}$, respectively, and (2) the final wash in TE buffer was omitted. Following the immunoprecipitation procedure, DNA was recovered by phenol/ chloroform extraction and ethanol precipitation.

Prior to the experiments, to confirm assay specificity, the presence of acH3 protein in anti-acH3 immunoprecipitations was confirmed by immunoblotting. The absence of acH3 in negative control nonimmune IgG (Upstate Biotechnology) immunoprecipitations was also established (data not shown). In the experiments, to control nonspecific immunoprecipitation of DNA, a parallel immunoprecipitation with nonimmune IgG was performed on a separate aliquot of each sample. qPCR for each primer pair was performed on all of these negative controls. If anti-acH3 qPCR quantitation was not greater than 1.5 times the IgGnegative control the sample was excluded from analysis for excessive nonspecific immunoprecipitation. One sample from the 1-day group was excluded from all analyses based on this preset value, leaving $n \geqslant 4$ for each group.

qPCR analysis of immunoprecipitated DNA was conducted using previously described and newly developed primers for c-fos, EGR1, Nr4a1, Arc, CART, NPY, Cdk5, $\beta$-tubulin, and $\varepsilon$-globin (see Supplementary Table 2 for primer sequences and references). Primers were designed to amplify $<200$ bp encompassing known promoter sites and/ or the transcription start sites if promoters were uncharacterized. Initially, two primers were designed for each gene and quality was established with PCR and dissociation curve analysis.

DNA (5 ng) from each immunoprecipitated sample and IgG-negative control was amplified by PCR using $5 \mu$ Power SYBR-Green (Applied Biosystems) and primer concentrations at $0.4 \mu \mathrm{M}$. Cycling parameters for all PCR reactions were as follows: 45 cycles of $94^{\circ} \mathrm{C}$ for $15 \mathrm{~s}, 53^{\circ} \mathrm{C}$ for $30 \mathrm{~s}$, and $72^{\circ} \mathrm{C}$ for $30 \mathrm{~s}$. Ct values from each sample were obtained using SDS2.2.2 RQ software (Applied Biosystems). Relative amount of template DNA was calculated using the formula: relative amount $=2^{-\Delta \mathrm{Ct}} \times 100 ;-\Delta \mathrm{Ct}=(\mathrm{Ct}$ gene- $\mathrm{Ct} \beta$ tubulin).

\section{Statistics}

Significance was determined by one-way analysis of variance (ANOVA) with a Student-Newmans-Keuls (SNK) post hoc test with significance at $p<0.05$. Multiple testing correction was applied at the ANOVA level on a gene by gene basis.

\section{RESULTS}

\section{Behavioral Data}

As described previously, when conditions were switched from an FR1 to a DT4 schedule of reinforcement, rats selfadministered nearly every injection for $18-36 \mathrm{~h}$ (ie the 'initial binge'; Roberts et al, 2002) and, over several days, responding became more circadian with increasing levels of intake through the dark phase and decreasing levels of intake through the light phase (for individual animal examples of these patterns, see McCracken et al, 2005; Morgan et al, 2002, 2005). Across this 10-day period, all four groups of rats used in the extinction experiments averaged approximately 50 infusions/day (Figure 2a) for total intakes of approximately $800 \mathrm{mg} / \mathrm{kg}$ over the 10 sessions (Figure 2b). Previous studies indicated that these patterns of self-administration coupled with at least a 7-day forced abstinence period result in higher levels of responding being maintained by cocaine on a progressive ratio schedule, whereas 1 day of forced abstinence fails to alter such responding (Morgan et al, 2002, 2005). In the present experiment, the effects of various durations of forced abstinence on extinction responding were studied (Group I, see schematic of treatment in Figure 1). There was a timerelated increase in the levels of extinction responding across the four groups of rats $\left(\mathrm{F}_{3,24}=5.64, p<0.005\right)$, with responses following 30 or 100 days of forced abstinence being significantly higher than those following 3 days of forced abstinence (Figure 2c). A nonsignificant increase in extinction responding was also evident at 10 days of forced abstinence.

In the set of rats generated for gene expression analysis (Group II; Figure 1) and the third set generated for chromatin remodeling studies (Group III; Figure 1), similar patterns of self-administration were observed across the 10 days of DT4 schedule responding (Figure 3a). A 1-day 

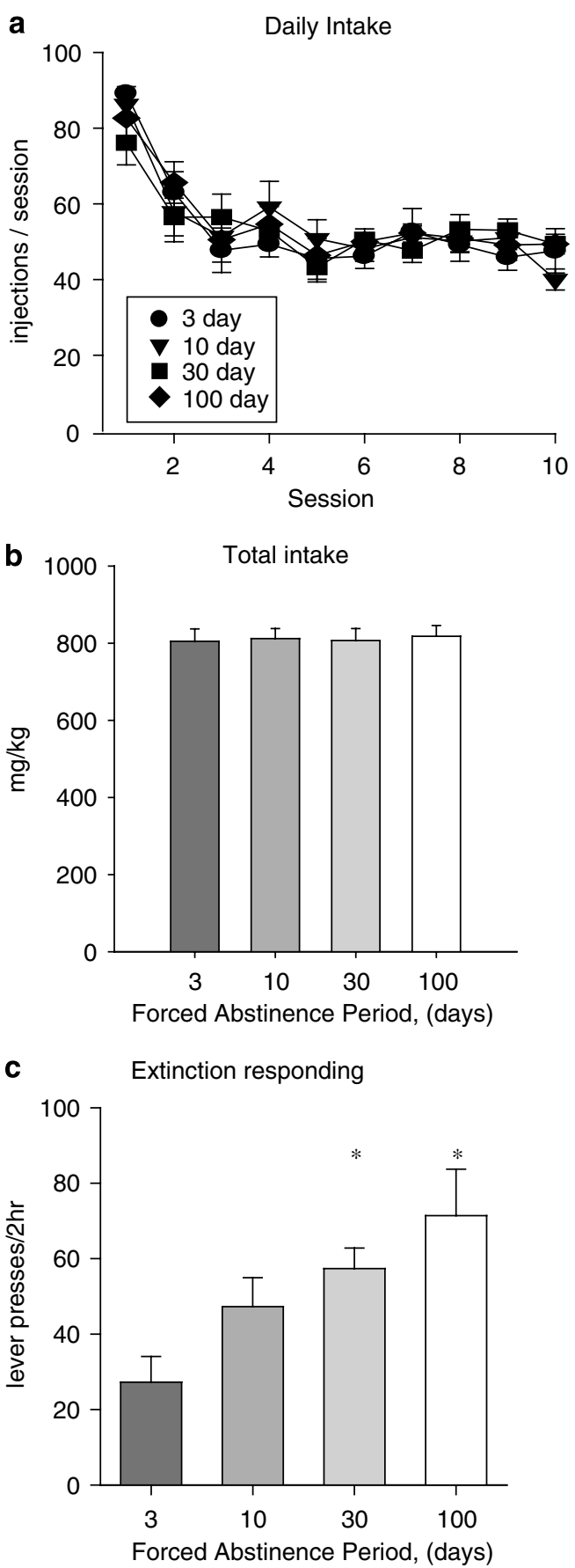

Figure 2 Time-dependent increases in cocaine-seeking after forced abstinence. (a) Four groups of rats engaged in self-administration training and discrete-trial 4 (DT4) self-administration for 10 days. No significant differences were observed across the self-administration time course. (b) As well, total cocaine intake between the groups did not differ. (c) After 3, 10,30 , or 100 days of forced abstinence, rats were returned to their operant chambers and engaged in responding for $2 \mathrm{~h}$ in which responses on the active lever produced an infusion of saline. Significant increases in total extinction responding were evident after 30 and 100 days of forced abstinence $(p<0.005)$ as compared to the rats abstinent for 3 days. The I0-day group also had higher total numbers of responses that approached significance. All data are mean \pm SEM, $* p<0.05$. abstinence period was used to provide consistency with our previous reports (Mateo et al, 2005; McCracken et al, 2005; Morgan et al, 2006). No differences in daily intake (Figure 3a) or total intake were observed between groups (Figure 3b). A slightly lower total intake was observed in the 10-day abstinent rats of Group II, but there were no significant differences with other groups $(p>0.05)$. The consistency of self-administration is evident across all three sets of rats generated (cf, Figures 2 and 3 ).

\section{Molecular Data}

Gene expression analysis was concentrated on a selected set of known cocaine-responsive genes to address whether these previously described genes exhibited altered expression levels with discrete-trial cocaine self-administration and following forced abstinence. These transcripts were chosen due to their well-documented responsiveness in the literature across several cocaine administration procedures. The goal of examining this set of rats was to determine if changes in transcripts would persist for over 3 months of forced abstinence.

Immediate early genes. A common profile was found for the four immediate early genes examined (c-fos, EGR1, Arc, and Nr4a1) (Figure 4). In the NAc, significant decreases were evident for all four genes at 100 days of abstinence as compared to controls (Arc $\left(\mathrm{F}_{3,29}=6.81, p<0.05\right)$; EGR1 $\left(\mathrm{F}_{3,29}=3.64, p<0.05\right)$; $\mathrm{c}$-fos $\left(\mathrm{F}_{3,29}=7.07, p<0.001\right)$; Nr4a1 $\left.\left(\mathrm{F}_{3,29}=3.39, p<0.05\right)\right)$. For EGR1 and $\mathrm{c}$-fos this decrease was also observed at 1 and 10 days of abstinence, while Nr4a1 and Arc transcript levels were decreased to a nonsignificant extent at 1 and 10 days of abstinence.

Similar temporal profiles were also observed in the mPFC for all four genes. Nr4a1 $\left(\mathrm{F}_{3,29}=5.42, p<0.01\right)$ and $\mathrm{c}$-fos $\left(\mathrm{F}_{3,29}=7.57, p<0.001\right) \quad \mathrm{mRNA}$ levels were significantly decreased in the mPFC at 1,10 , and 100 days of abstinence. Arc expression $\left(\mathrm{F}_{3,29}=6.81, p<0.001\right)$ was significantly lower at 1 and 100 days of abstinence while EGR1 $\left(\mathrm{F}_{3,29}=3.91, p<0.05\right)$ was only significantly decreased at 1 day of abstinence. For all of these genes and in both the mPFC and NAc, no statistically significant differences were observed between 1-, 10-, and 100-day abstinence gene expression levels.

Neuropeptides. Two different known cocaine-responsive signaling molecules (CART and NPY) were examined (Figure 5). The neuropeptides CART $\left(\mathrm{F}_{3,29}=11.21\right.$, $p<0.001)$ and NPY $\left(\mathrm{F}_{3,29}=6.37, p<0.01\right)$ were specifically increased in the $\mathrm{mPFC}$ at 1 day of abstinence, but this change did not persist with prolonged abstinence. No changes in expression of these transcripts were observed in the NAc.

Other transcripts. A panel of glutamate receptor (Grial, Gria2, and Grin1), receptor complex (Homer $1 \mathrm{~b} / \mathrm{c}$ and Homer 2), and glutamate-related kinase (Cdk5) transcripts were also examined (Table 1). Unlike the transcript levels of immediate early genes and neuropeptides, no changes in expression levels were found in the mPFC and NAc. Transcript levels were extremely consistent with no signal time point varying from control by more that $15 \%$. 
Chromatin remodeling. The finding that some of the gene expression changes persisted for up to 100 days suggests a more permanent form of regulation than acute cocaine action. In a pilot study of chromatin remodeling as a potential regulatory mechanism for these changes in gene
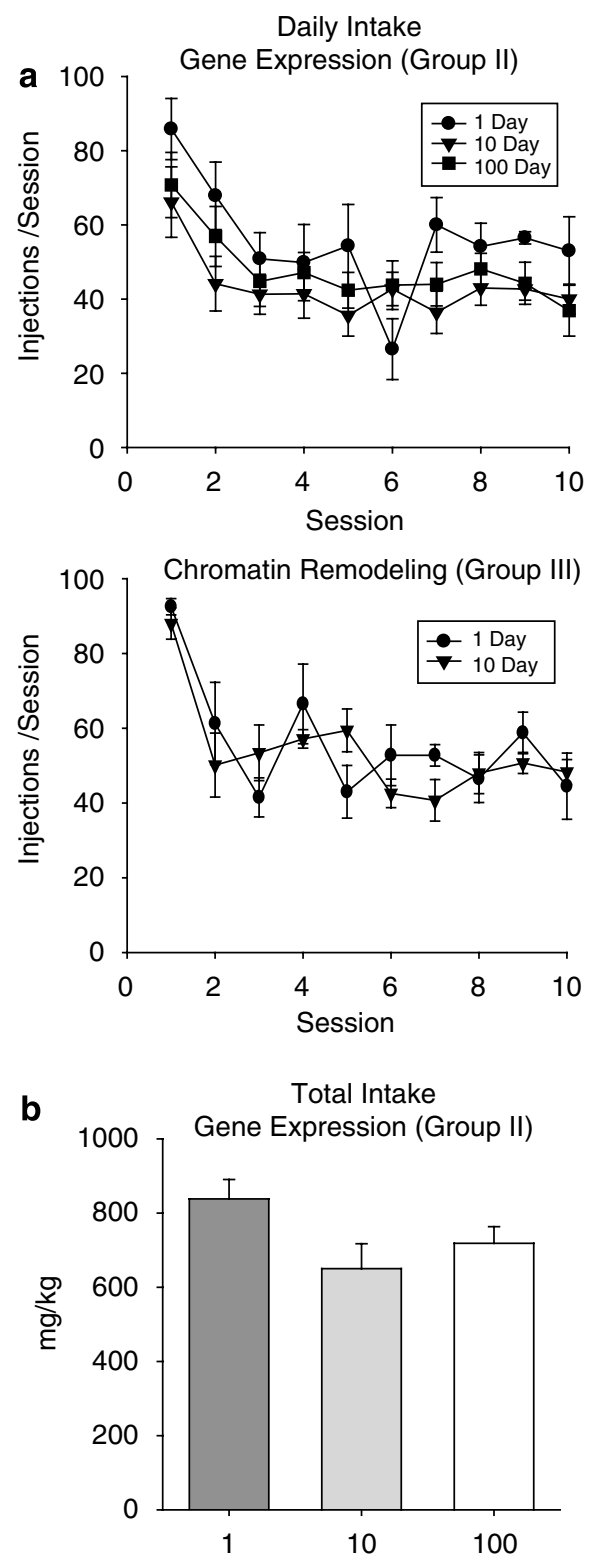

Forced Abstinence Period, (days)

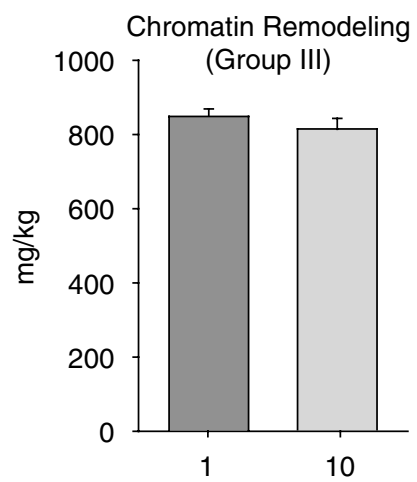

Forced Abstinence Period, (days) expression, ChIP against acetylated Histone H3 K9-14 was performed on formaldehyde-fixed mPFC tissue. qPCR was performed against promoter regions of genes found to have altered mRNA expression levels (EGR1, Nr4a1, Fos, Arc, CART, and NPY). Significant decreases in K9-14 acetylated histone H3-bound EGR1 $\left(\mathrm{F}_{2,10}=5.45, p<0.05\right)$ promoter were observed at 1 and 10 days of abstinence compared to naive controls (Figure 6). The magnitude of the decreases (39\% at 1 day and $40 \%$ at 10 days) is very close to those of the mRNA levels at 1 and 10 days of abstinence (40 and $28 \%$, respectively). For NPY, a significantly higher level $\left(\mathrm{F}_{2,10}=4.01, p<0.05\right)$ of acetylated histone $\mathrm{H} 3$ bound to the NPY promoter was found at 1 day of abstinence as compared to control and 10-day abstinent rats. The magnitude of the increase again closely followed that of the mRNA levels with $24 \%$ higher levels of acetylated H3bound NPY promoter compared to $22 \%$ higher mRNA levels in 1-day abstinent rats compared to controls. However, in spite of the close chromatin/mRNA correlation for EGR1 and NPY, no changes in K9-14 acetylated histone $\mathrm{H} 3$ bound to Nr4a1, Fos, Arc, or CART gene promoters were observed (data not shown).

\section{DISCUSSION}

In examining the relationship between the molecular and behavioral changes, it is possible to speculate on the roles of molecular adaptations in the development and/or expression of increased drug-seeking and reinforcing efficacy. This study and previous reports using the DT4 model have established that there is an increase in drug-seeking and reinforcing efficacy measures beginning at 7 days of abstinence and still evident at 100 days of abstinence. Clearly, some form of incubation is occurring in the first week of abstinence and these changes then persist for months, in a manner similar to the previous work of Shaham, Hope, and colleagues (Shaham and Hope, 2005; Lu et al, 2004).

The gene expression results demonstrate that molecular changes persist even following 100 days of forced abstinence. Rats generated for the gene expression and chromatin experiments did not undergo the extinction session to avoid extinction responding-induced gene expression changes. It is noteworthy that the genes displayed different temporal expression profiles. Decreases in all of the immediate early genes examined were evident at 1 day of forced abstinence either in the mPFC or NAc. The increased extinction responding observed at 30 and 100 days of forced abstinence and our previous examinations of progressive ratio breakpoints (Morgan et al, 2002, 2005) indicate that at least 7-10 days of forced abstinence is

Figure 3 Self-administration history for rats used in molecular studies. To avoid any confounds of extinction sessions, separate sets of rats were collected for molecular biology experiments assessing gene expression and chromatin remodeling. Based on the previous findings of this study and previous reports, rats were subjected to 10 days of DT4 cocaine selfadministration with either I, 10, or 100 days of forced abstinence. (a) Mean daily intake of rats from Groups II and III did not differ across the 10 days of self-administration. (b) No differences in total intake were observed between the self-administration groups. All data are mean \pm SEM. 

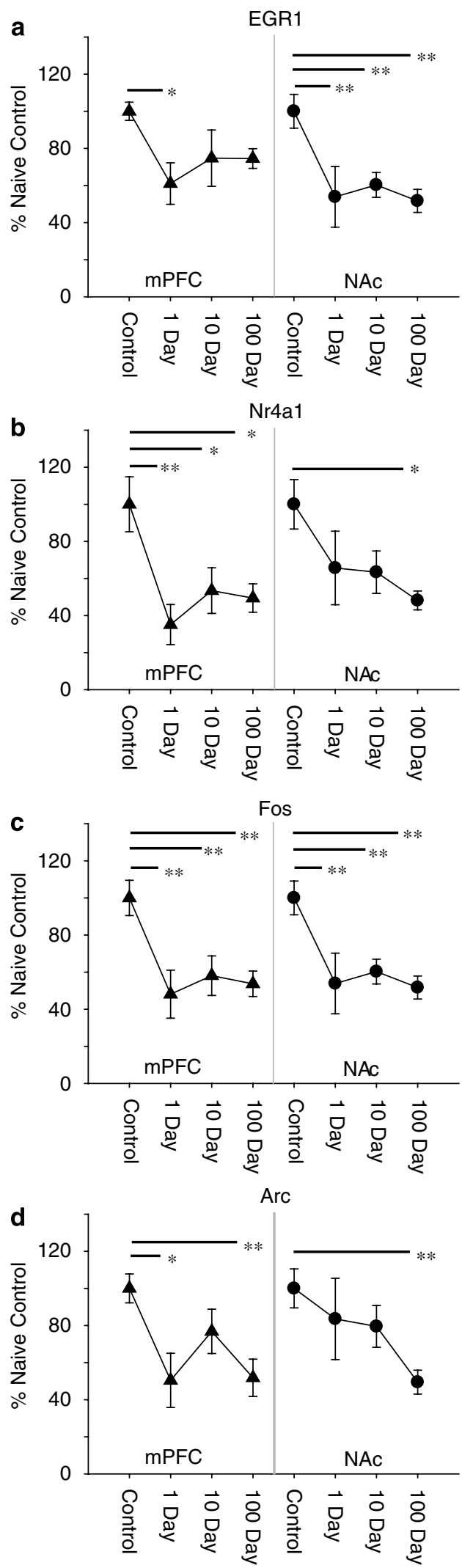

Figure 4 Immediate early genes. The expression of the immediate early genes EGRI (a), Nr4al (b), fos (c), and Arc (d) were determined by qRTPCR in the medial prefrontal cortex (mPFC) and nucleus accumbens (NAc) in control rats and after I, 10 , or 100 days of forced abstinence. Persistent decreases in all four genes were found in both the mPFC and NAc. All data are mean $\pm \mathrm{SEM},{ }^{*} p<0.05$, ${ }^{*} p<<0.0$ I one-way ANOVA, SNK post hoc test.
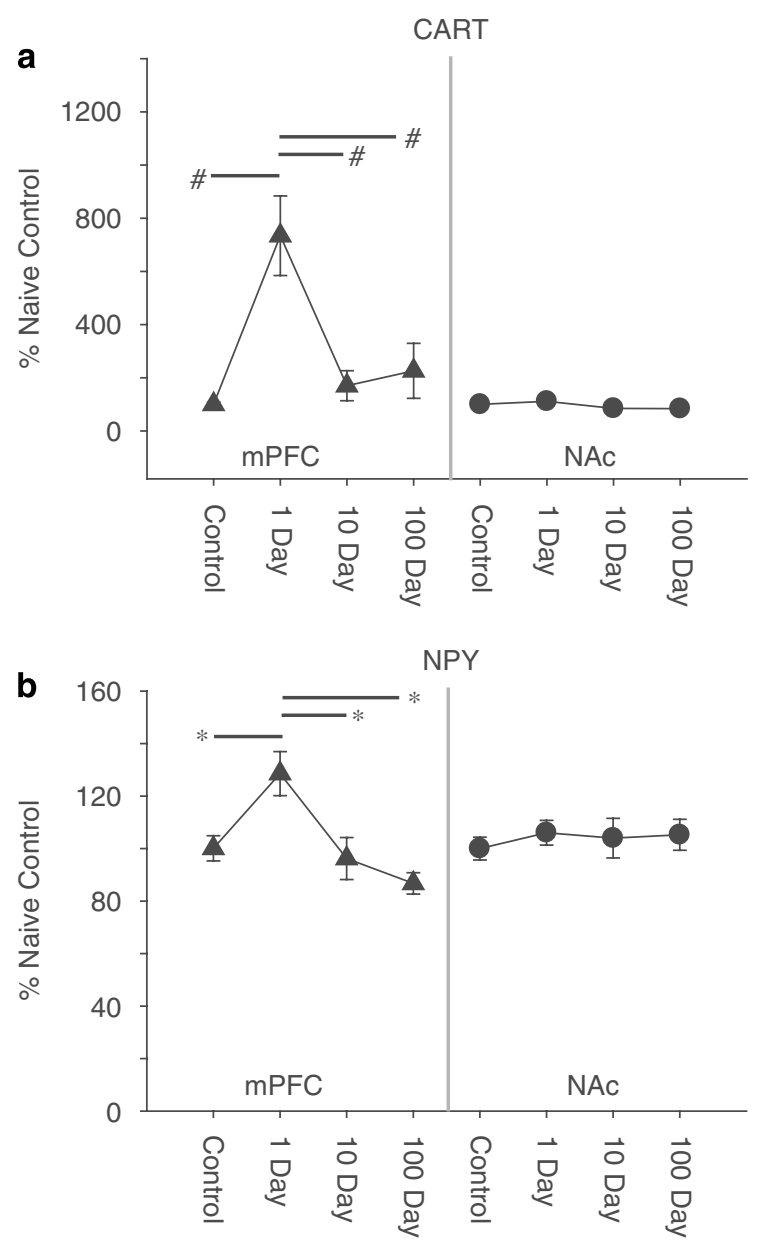

Figure 5 Neuropeptides. The expression of the neuropeptides CART (a) and neuropeptide $Y$ (NPY, b) was determined by qRT-PCR in the mPFC and NAc in control rats and after 1, 10, or 100 days of forced abstinence. CART and NPY medial prefrontal cortex (mPFC) mRNA levels were elevated in I-day abstinent rats as compared to controls but returned to baseline levels by 10 days of forced abstinence. All data are mean \pm SEM, ${ }^{*} p<0.05,{ }_{p}<0.00$ I one-way ANOVA, SNK post hoc test.

required for the incubation of behavioral changes. The fact that gene expression changes are occurring before the behavioral changes may indicate that these genes contribute to the development of the behavioral phenotype. As such, they may play a role in development of the incubation phenotype through the secondary effects they cause (McClung and Nestler, 2003). Further studies will be needed to address whether their induction returns with relapse of cocaine self-administration following forced abstinence. The continued repression of these genes even after 100 days of forced abstinence suggests that they may also play a role in the expression of the incubation phenotype.

Both of the neuropeptides NPY and CART are significantly increased in the MPFC at 1 day of forced abstinence, but return to normal levels with 10 or 100 days of abstinence. These changes would seem to be in response to cocaine self-administration and do not continue with removal of the cocaine stimulus. Further studies will be needed to address whether their induction returns with relapse of cocaine self-administration following extended periods of forced abstinence. 
Table I Gene Expression Unchanged by DT4/Abstinence Self-Administration Paradigm

\begin{tabular}{lrr}
\hline & MPFC & \multicolumn{1}{c}{ NAc } \\
\hline Cdk5 & & \\
Naive & $1.0 \pm 0.14$ & $1.0 \pm 0.08$ \\
I day & $0.85 \pm 0.08$ & $0.95 \pm 0.11$ \\
I0 day & $0.91 \pm 0.10$ & $1.07 \pm 0.11$ \\
100 day & $0.93 \pm 0.07$ & $0.99 \pm 0.18$
\end{tabular}

$$
\begin{aligned}
& \text { Gria I } \\
& \text { Naive } \\
& \text { I day } \\
& 10 \text { day }
\end{aligned}
$$

100 day

\section{Gria2 \\ Naive \\ I day \\ 10 day}

100 day

$$
\begin{aligned}
& \text { Grin I } \\
& \text { Naive } \\
& \text { I day } \\
& \text { I0 day }
\end{aligned}
$$

100 day

$$
\begin{gathered}
\text { Homer lb/c } \\
\text { Naive } \\
1 \text { day } \\
10 \text { day } \\
100 \text { day }
\end{gathered}
$$

Homer 2

$$
\text { Naive }
$$$$
\text { I day }
$$$$
10 \text { day }
$$$$
\text { I00 day }
$$

$1.0 \pm 0.04$
$1.06 \pm 0.05$
$1.05 \pm 0.04$
$0.98 \pm 0.04$

$1.0 \pm 0.03$

$0.98 \pm 0.05$

$0.97 \pm 0.06$

$0.96 \pm 0.05$

$1.0 \pm 0.05$

$0.96 \pm 0.04$

$0.81 \pm 0.09$

$0.95 \pm 0.11$

$1.0 \pm 0.04$

$1.07 \pm 0.05$

$0.94 \pm 0.06$

$0.94 \pm 0.08$

$1.0 \pm 0.04$

$1.0 \pm 0.08$

$0.98 \pm 0.04$

$0.94 \pm 0.06$
Abbreviations: mPFC, medial prefrontal cortex; NAc, nucleus accumbens. Glutamate receptor complex genes mRNA levels. No significant changes were observed for any of the glutamate receptor complex genes in either brain region or at any time point. All data are mean \pm SEM.

The individual genes found to be altered in their expression have a number of points of convergence with the existing cocaine literature. First, the neuropeptide CART was initially reported as an uncharacterized cocaineresponsive transcript by Douglass et al (1995). Subsequent work has determined that CART may play a critical role in the rewarding and reinforcing properties of natural rewards such as food and also psychostimulants (for review, see Jaworski and Jones, 2006). There has been some controversy as to the responsiveness of CART to psychostimulant administration with reports demonstrating increases in NAc
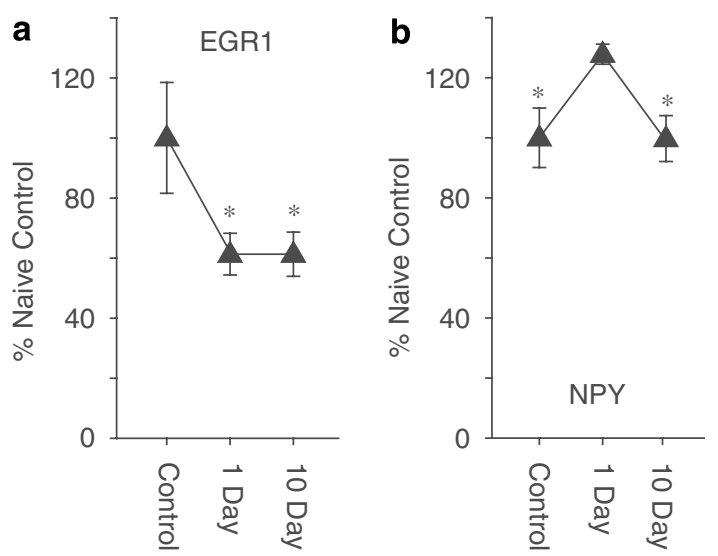

Figure 6 Acetylated histone $\mathrm{H} 3$ (K9-14) at specific gene promoters. As measured by ChIP-qPCR, decreased levels were observed in the mPFC for EGRI (a) at I and IO days of abstinence, $* p<0.05$, one-way ANOVA, SNK post hoc test vs controls. Acetylated H3 levels at the neuropeptide Y (NPY) promoter (b) were higher at I day of abstinence as compared to control and 10 days of abstinence, ${ }^{*} p<0.05$, one-way ANOVA, SNK post hoc test vs I day. All data are mean \pm SEM.

mRNA levels (Brenz Verca et al, 2001; Fagergren and Hurd, 1999) and a possible dependency on binge administration (Hunter et al, 2005), while other reports finding no differences (Marie-Claire et al, 2003). We observed no changes in accumbal CART mRNA levels, but instead observed a novel and dramatic increase in mPFC mRNA levels (over six times higher than controls). While much of the existing literature on cocaine-responsive CART mRNA expression has been in the NAc, equivalent levels of expression are found in prefrontal cortices (Hurd and Fagergren, 2000). As previously noted (Jaworski and Jones, 2006), precise definitions of CART's role in rewarding properties of cocaine remain to be made, but CART knockout mice respond less for cocaine and have lower cocaine intake than wild-type mice. If ablation of the CART gene reduces cocaine intake, increases such as those seen in this study may have the opposite effect.

NPY is a 36 amino acid peptide that is widely distributed throughout the nervous system. While NPY has been extensively studied in alcohol abuse (Thiele and BadiaElder, 2003), reports relating to NPY and cocaine abuse are less abundant. Most relevant is a report of decreased frontal cortex NPY mRNA for up to 6 weeks of forced abstinence following 1 week of noncontingent cocaine administration (Wahlestedt et al, 1991). This is the opposite of our findings and the most likely basis of this difference is the dissimilar mode and dose of cocaine administered. The significant increase in acetylated histone $\mathrm{H} 3$ at the NPY promoter at 1 day of abstinence is in agreement with the gene expression data as actetylated histone H3 (K9-14) is associated with increased transcription (Roh et al, 2005). The return to levels of control rats of acetylated histone $\mathrm{H} 3$ at 10 days mirrors the return to levels of the mRNA abundance in the drug-naive rats.

The responsivity of EGR1, also known as NGFI-A, krox24, and zif268, to cocaine administration has been known for over a decade (Helton et al, 1993; Moratalla et al, 1992). More recently though, decreases in EGR1 mRNA expression 
have been documented during forced abstinence from highdose cocaine self-administration binges (Mutschler et al, 2000). The potential importance of EGR1 in cocaine-related behaviors has been demonstrated in antisense injection and mutant mouse experiments (Lee et al, 2005, 2006; Valjent et al, 2006).

The finding of decreases in histone $\mathrm{H} 3$ acetylation at 1 and 10 days of abstinence suggests a decrease in active transcription of EGR1. The previous report of increased acetylated histone $\mathrm{H} 3$ at specific promoters following cocaine self-administration was restricted to 1 day after the last self-administration session (Kumar et al, 2005). Our findings extend the timeline of histone modifications as persisting for up to 10 days. Examination of longer abstinence periods and histone acetylation at promoters of genes with persistent expression changes is required in future studies. The work by Meany and colleagues has demonstrated that EGR1 is a target of epigenetic modification and that this manifests itself in persistently altered behavior (Weaver et al, 2004). The combination of the known behavioral relevance of EGR1 and known epigenetic modifications suggests that further specific study of EGR1 may be fruitful.

While fos induction is generally associated with cocaine administration, there have been reported decreases in mPFC fos with forced abstinence (Todtenkopf et al, 2002). The suppression of fos mRNA levels was similar in both the mPFC and NAc and occurred by 1 day of abstinence with no return toward control levels at 10 or 100 days of abstinence. Unlike the previous examination of histone $\mathrm{H} 3$ acetylation at the Fos promoter with chronic cocaine self-administration that found increases (Kumar et al, 2005), no changes were observed in this study. This may be due to the difference in the cocaine self-administration procedure: DT4 in this study and FR1 in the previous report.

Nr4a1, known previously as NGFI-B/Nur77, is a nuclear orphan receptor expressed in many dopaminergic terminal regions (Zetterstrom et al, 1996). Previously, both we and others have described induction of mPFC and/or NAc mRNA levels of Nr4al with noncontingent and selfadministered cocaine (Werme et al, 2000; Freeman et al, $2002 \mathrm{ab}$ ). As with the other immediate early genes, we found long-lasting decreases in mRNA expression in opposition to the previous reports of acute induction with cocaine administration.

Arc induction was first reported by Fosnaugh et al (1995). Previously, we found increases in Arc protein in the mPFC after chronic noncontingent (Freeman et al, 2002a), but not self-administered, cocaine (Freeman et al, 2002b). Recently, a temporal analysis of Arc protein levels was examined after noncontingent cocaine administration (Fumagalli et al, 2006). Increases in mPFC levels were found to occur during the initial hours of forced abstinence, but the levels returned to baseline within 1 day for a single administration and 2 weeks following chronic administration (Fumagalli et al, 2006). Most relevant to this report, induction of Arc mRNA within the mPFC and NAc was greater when cocaine was infused rapidly in a manner that engendered locomotor sensitization (Samaha et al, 2004).

No changes in glutamate receptor transcripts, previously described as cocaine responsive, were found in the study. In fact, all of the transcripts varied less than $15 \%$ from control values in either brain region or at any time point. This finding may reflect different administration procedures. For example, the previous report of Gria2 induction in the mPFC used noncontingent administration (Ghasemzadeh et al, 1999) and previous reports clearly indicate that contingency affects the gene expression response (Mutschler et al, 2000). The most similar previous report of expression changes with long-term abstinence following cocaine self-administration (Lu et al, 2003) examined protein expression levels. While we have previously found close correlations between cocaine-responsive mRNA and protein expression (Freeman et al, 2001b), we have also described changes in protein expression that are not always accompanied by mRNA expression changes, depending on the brain region (Bennett et al, 1999). Future protein expression studies of these glutamatergic genes and the other genes examined will be needed.

In total, these data point to several novel findings. Behaviorally, the DT4 paradigm can engender increases in drug-seeking that persist for up to 100 days of drug abstinence. At the molecular level, there is persistent depression of several immediate early genes in both the NAc and mPFC for up to 100 days. This repression of gene expression suggests that long-term forced abstinence may present opposing gene expression changes to acute cocaineinduced changes. Last, for at least some of these genes, expression may be in part controlled through histone modifications.

\section{ACKNOWLEDGEMENTS}

This study was supported by NIH grants F31DA022819 (to MEL), R01DA014030 (to DCSR), K01DA13957 (to DM) and R01DA013770 (to KEV), and a NARSAD Young Investigator Award (to WMF). We thank Trevor Smith for assistance in manuscript preparation, and Leanne Thomas for excellent technical assistance.

\section{DISCLOSURE/CONFLICT OF INTEREST}

The authors have no potential conflicts of interest.

\section{REFERENCES}

Bennett SA, Arnold JM, Chen J, Stenger J, Paul DL, Roberts DC (1999). Long-term changes in connexin32 gap junction protein and mRNA expression following cocaine self-administration in rats. Eur J Neurosci 11: 3329-3338.

Bisaga A, Aharonovich E, Garawi F, Levin FR, Rubin E, Raby WN et al (2006). A randomized placebo-controlled trial of gabapentin for cocaine dependence. Drug Alcohol Depend 81: 267-274.

Boudreau AC, Wolf ME (2005). Behavioral sensitization to cocaine is associated with increased AMPA receptor surface expression in the nucleus accumbens. J Neurosci 25: 9144-9151.

Bowyer JF, Pogge AR, Delongchamp RR, O'callaghan JP, Patel KM, Vrana KE et al (2007). A threshold neurotoxic amphetamine exposure inhibits parietal cortex expression of synaptic plasticity-related genes. Neuroscience 144: 66-76.

Brenz Verca MS, Widmer DA, Wagner GC, Dreyer J (2001). Cocaine-induced expression of the tetraspanin CD81 and its relation to hypothalamic function. Mol Cell Neurosci 17: 303-316. 
Carlezon Jr WA, Nestler EJ (2002). Elevated levels of GluR1 in the midbrain: a trigger for sensitization to drugs of abuse? Trends Neurosci 25: 610-615.

Childress AR, Mozley PD, McElgin W, Fitzgerald J, Reivich M, O’Brien CP (1999). Limbic activation during cue-induced cocaine craving. Am J Psychiatry 156: 11-18.

Chomczynski P, Mackey K (1995). Short technical reports. Modification of the TRI reagent procedure for isolation of RNA from polysaccharide- and proteoglycan-rich sources. Biotechniques 19: 942-945.

Dackis CA, Kampman KM, Lynch KG, Pettinati HM, O’Brien CP (2005). A double-blind, placebo-controlled trial of modafinil for cocaine dependence. Neuropsychopharmacology 30: 205-211.

Daunais JB, McGinty JF (1995). Cocaine binges differentially alter striatal preprodynorphin and zif/268 mRNAs. Brain Res Mol Brain Res 29: 201-210.

Douglass J, McKinzie AA, Couceyro P (1995). PCR differential display identifies a rat brain mRNA that is transcriptionally regulated by cocaine and amphetamine. J Neurosci 15: 2471-2481.

Fagergren P, Hurd YL (1999). Mesolimbic gender differences in peptide CART mRNA expression: effects of cocaine. Neuroreport 10: $3449-3452$.

Fosnaugh JS, Bhat RV, Yamagata K, Worley PF, Baraban JM (1995). Activation of arc, a putative 'effector' immediate early gene, by cocaine in rat brain. J Neurochem 64: 2377-2380.

Freeman WM, Brebner K, Lynch WJ, Patel KM, Robertson DJ, Roberts DC et al (2002a). Changes in rat frontal cortex gene expression following chronic cocaine. Brain Res Mol Brain Res 104: 11-20.

Freeman WM, Brebner K, Lynch WJ, Robertson DJ, Roberts DC, Vrana KE (2001a). Cocaine-responsive gene expression changes in rat hippocampus. Neuroscience 108: 371-380.

Freeman WM, Brebner K, Patel KM, Lynch WJ, Roberts DC, Vrana KE (2002b). Repeated cocaine self-administration causes multiple changes in rat frontal cortex gene expression. Neurochem Res 27: 1181-1192.

Freeman WM, Nader MA, Nader SH, Robertson DJ, Gioia L, Mitchell SM et al (2001b). Chronic cocaine-mediated changes in non-human primate nucleus accumbens gene expression. J Neurochem 77: 542-549.

Fumagalli F, Bedogni F, Frasca A, Di PL, Racagni G, Riva MA (2006). Corticostriatal up-regulation of activity-regulated cytoskeletal-associated protein expression after repeated exposure to cocaine. Mol Pharmacol 70: 1726-1734.

Gawin FH, Kleber HD (1986). Abstinence symptomatology and psychiatric diagnosis in cocaine abusers. Clinical observations Arch Gen Psychiatry 43: 107-113.

Ghasemzadeh MB, Nelson LC, Lu XY, Kalivas PW (1999). Neuroadaptations in ionotropic and metabotropic glutamate receptor mRNA produced by cocaine treatment. J Neurochem 72 : 157-165.

Gossop M, Marsden J, Stewart D, Kidd T (2003). The National Treatment Outcome Research Study (NTORS): 4-5 year followup results. Addiction 98: 291-303.

Graybiel AM, Moratalla R, Robertson HA (1990). Amphetamine and cocaine induce drug-specific activation of the c-fos gene in striosome-matrix compartments and limbic subdivisions of the striatum. Proc Natl Acad Sci USA 87: 6912-6916.

Grimm JW, Hope BT, Wise RA, Shaham Y (2001). Neuroadaptation. Incubation of cocaine craving after withdrawal. Nature 412: 141-142.

Helton TE, Daunais JB, McGinty JF (1993). Convulsant doses of cocaine alter immediate early gene and opioid peptide expression in rat limbic forebrain. Brain Res Mol Brain Res 20: 285-288.

Hunter RG, Vicentic A, Rogge G, Kuhar MJ (2005). The effects of cocaine on CART expression in the rat nucleus accumbens: a possible role for corticosterone. Eur J Pharmacol 517: 45-50.
Hurd YL, Fagergren P (2000). Human cocaine- and amphetamineregulated transcript (CART) mRNA is highly expressed in limbic- and sensory-related brain regions. J Comp Neurol 425: 583-598.

Jaworski JN, Jones DC (2006). The role of CART in the reward/ reinforcing properties of psychostimulants. Peptides 27: 19932004.

Kalivas PW, McFarland K (2003). Brain circuitry and the reinstatement of cocaine-seeking behavior. Psychopharmacology (Berl) 168: 44-56.

Kumar A, Choi KH, Renthal W, Tsankova NM, Theobald DE, Truong HT et al (2005). Chromatin remodeling is a key mechanism underlying cocaine-induced plasticity in striatum. Neuron 48: 303-314.

Lee JL, Di CP, Thomas KL, Everitt BJ (2005). Disrupting reconsolidation of drug memories reduces cocaine-seeking behavior. Neuron 47: 795-801.

Lee JL, Milton AL, Everitt BJ (2006). Cue-induced cocaine seeking and relapse are reduced by disruption of drug memory reconsolidation. J Neurosci 26: 5881-5887.

Livak KJ, Schmittgen TD (2001). Analysis of relative gene expression data using real-time quantitative PCR and the 2(-Delta Delta C(T)) method. Methods 25: 402-408.

Lu L, Dempsey J, Shaham Y, Hope BT (2005a). Differential longterm neuroadaptations of glutamate receptors in the basolateral and central amygdala after withdrawal from cocaine selfadministration in rats. J Neurochem 94: 161-168.

$\mathrm{Lu} \mathrm{L}$, Grimm JW, Hope BT, Shaham Y (2004). Incubation of cocaine craving after withdrawal: a review of preclinical data. Neuropharmacology 47(Suppl 1): 214-226.

$\mathrm{Lu}$ L, Grimm JW, Shaham Y, Hope BT (2003). Molecular neuroadaptations in the accumbens and ventral tegmental area during the first 90 days of forced abstinence from cocaine selfadministration in rats. J Neurochem 85: 1604-1613.

Lu L, Hope BT, Dempsey J, Liu SY, Bossert JM, Shaham Y (2005b). Central amygdala ERK signaling pathway is critical to incubation of cocaine craving. Nat Neurosci 8: 212-219.

Lu L, Uejima JL, Gray SM, Bossert JM, Shaham Y (2007). Systemic and central amygdala injections of the mGluR(2/3) agonist LY379268 attenuate the expression of incubation of cocaine craving. Biol Psychiatry 61: 591-598.

Maley D, Mei J, Lu H, Johnson DL, Ilyin SE (2004). Multiplexed RT-PCR for high throughput screening applications. Comb Chem High Throughput Screen 7: 727-732.

Marcellino D, Roberts DC, Navarro G, Filip M, Agnati L, Lluis C et al (2007). Increase in A2A receptors in the nucleus accumbens after extended cocaine self-administration and its disappearance after cocaine withdrawal. Brain Res 1143: 208-220.

Marie-Claire C, Laurendeau I, Canestrelli C, Courtin C, Vidaud M, Roques B et al (2003). Fos but not Cart (cocaine and amphetamine regulated transcript) is overexpressed by several drugs of abuse: a comparative study using real-time quantitative polymerase chain reaction in rat brain. Neurosci Lett 345: 77-80.

Mateo Y, Lack CM, Morgan D, Roberts DC, Jones SR (2005). Reduced dopamine terminal function and insensitivity to cocaine following cocaine binge self-administration and deprivation. Neuropsychopharmacology 30: 1455-1463.

McClung CA, Nestler EJ (2003). Regulation of gene expression and cocaine reward by CREB and DeltaFosB. Nat Neurosci 6: 1208-1215.

McCracken CB, Hamby SM, Patel KM, Morgan D, Vrana KE, Roberts DC (2005). Extended cocaine self-administration and deprivation produces region-specific and time-dependent changes in connexin36 expression in rat brain. Synapse 58: 141-150.

Moratalla R, Robertson HA, Graybiel AM (1992). Dynamic regulation of NGFI-A (zif268, egr1) gene expression in the striatum. J Neurosci 12: 2609-2622. 
Morgan D, Brebner K, Lynch WJ, Roberts DC (2002). Increases in the reinforcing efficacy of cocaine after particular histories of reinforcement. Behav Pharmacol 13: 389-396.

Morgan D, Liu Y, Roberts DC (2006). Rapid and persistent sensitization to the reinforcing effects of cocaine. Neuropsychopharmacology 31: 121-128.

Morgan D, Roberts DC (2004). Sensitization to the reinforcing effects of cocaine following binge-abstinent self-administration. Neurosci Biobehav Rev 27: 803-812.

Morgan D, Smith MA, Roberts DC (2005). Binge self-administration and deprivation produces sensitization to the reinforcing effects of cocaine in rats. Psychopharmacology (Berl) 178: 309-316.

Mutschler NH, Miczek KA, Hammer Jr RP (2000). Reduction of zif268 messenger RNA expression during prolonged withdrawal following 'binge' cocaine self-administration in rats. $\mathrm{Neu}$ roscience 100: 531-538.

Nestler EJ (2004). Historical review: molecular and cellular mechanisms of opiate and cocaine addiction. Trends Pharmacol Sci 25: 210-218.

O’Brien CP (2005). Anticraving medications for relapse prevention: a possible new class of psychoactive medications. Am J Psychiatry 162: 1423-1431.

O'Brien CP (1996). Recent developments in the pharmacotherapy of substance abuse. J Consult Clin Psychol 64: 677-686.

O'Brien CP, Childress AR, Ehrman R, Robbins SJ (1998). Conditioning factors in drug abuse: can they explain compulsion? J Psychopharmacol 12: 15-22.

Paxinos G, Watson C (2004). The Rat Brain in Stereotaxic Coordinates. Elsevier: New York.

Rebec GV, Sun W (2005). Neuronal substrates of relapse to cocaine-seeking behavior: role of prefrontal cortex. J Exp Anal Behav 84: 653-666.

Risinger RC, Salmeron BJ, Ross TJ, Amen SL, Sanfilipo M, Hoffmann RG et al (2005). Neural correlates of high and craving during cocaine self-administration using BOLD fMRI. Neuroimage 26: 1097-1108.

Roberts DC, Brebner K, Vincler M, Lynch WJ (2002). Patterns of cocaine self-administration in rats produced by various access conditions under a discrete trials procedure. Drug Alcohol Depend 67: 291-299.

Roberts DC, Goeders NE (1989). Drug self-administration: experimental methods and determinants. In: Boulton AA, Baker GB, Greenshaw AJ (eds). Neuromethods: Psychopharmacology. Clifton, NJ, USA, Humana, pp 349-398.

Roh TY, Cuddapah S, Zhao K (2005). Active chromatin domains are defined by acetylation islands revealed by genome-wide mapping. Genes Dev 19: 542-552.

Rohsenow DJ, Monti PM, Martin RA, Michalec E, Abrams DB (2000). Brief coping skills treatment for cocaine abuse: 12-month substance use outcomes. J Consult Clin Psychol 68: 515-520.

Samaha AN, Mallet N, Ferguson SM, Gonon F, Robinson TE (2004). The rate of cocaine administration alters gene regulation and behavioral plasticity: implications for addiction. J Neurosci 24: 6362-6370.

Shaham Y, Hope BT (2005). The role of neuroadaptations in relapse to drug seeking. Nat Neurosci 8: 1437-1439.

Sinha R (2001). How does stress increase risk of drug abuse and relapse? Psychopharmacology (Berl) 158: 343-359.
Sutton MA, Schmidt EF, Choi KH, Schad CA, Whisler K, Simmons $\mathrm{D}$ et al (2003). Extinction-induced upregulation in AMPA receptors reduces cocaine-seeking behaviour. Nature 421: 70-75.

Szumlinski KK, Abernathy KE, Oleson EB, Klugmann M, Lominac $\mathrm{KD}, \mathrm{He} \mathrm{DY}$ et al (2006). Homer isoforms differentially regulate cocaine-induced neuroplasticity. Neuropsychopharmacology 31: 768-777.

Taepavarapruk P, Phillips AG (2003). Neurochemical correlates of relapse to $d$-amphetamine self-administration by rats induced by stimulation of the ventral subiculum. Psychopharmacology (Berl) 168: 99-108.

Thiele TE, Badia-Elder NE (2003). A role for neuropeptide $Y$ in alcohol intake control: evidence from human and animal research. Physiol Behav 79: 95-101.

Todtenkopf MS, Mihalakopoulos A, Stellar JR (2002). Withdrawal duration differentially affects c-fos expression in the medial prefrontal cortex and discrete subregions of the nucleus accumbens in cocaine-sensitized rats. Neuroscience 114: 10611069.

Tsankova NM, Kumar A, Nestler EJ (2004). Histone modifications at gene promoter regions in rat hippocampus after acute and chronic electroconvulsive seizures. J Neurosci 24: 5603-5610.

Valjent E, Aubier B, Corbille AG, Brami-Cherrier K, Caboche J, Topilko P et al (2006). Plasticity-associated gene Krox24/Zif268 is required for long-lasting behavioral effects of cocaine. $J$ Neurosci 26: 4956-4960.

Volkow ND, Wang GJ, Ma Y, Fowler JS, Wong C, Ding YS et al (2005). Activation of orbital and medial prefrontal cortex by methylphenidate in cocaine-addicted subjects but not in controls: relevance to addiction. J Neurosci 25: 3932-3939.

Vorel SR, Liu X, Hayes RJ, Spector JA, Gardner EL (2001). Relapse to cocaine-seeking after hippocampal theta burst stimulation. Science 292: 1175-1178.

Wahlestedt C, Karoum F, Jaskiw G, Wyatt RJ, Larhammar D, Ekman $\mathrm{R}$ et al (1991). Cocaine-induced reduction of brain neuropeptide $\mathrm{Y}$ synthesis dependent on medial prefrontal cortex. Proc Natl Acad Sci USA 88: 2078-2082.

Wallace BC (1989). Psychological and environmental determinants of relapse in crack cocaine smokers. J Subst Abuse Treat 6: 95-106.

Ward SJ, Lack C, Morgan D, Roberts DC (2006). Discrete-trials heroin self-administration produces sensitization to the reinforcing effects of cocaine in rats. Psychopharmacology (Berl) 185: 150-159.

Weaver IC, Cervoni N, Champagne FA, D'Alessio AC, Sharma S, Seckl JR, et al (2004). Epigenetic programming by maternal behavior. Nat Neurosci 7: 847-854.

Werme M, Olson L, Brene S (2000). NGFI-B and nor1 mRNAs are upregulated in brain reward pathways by drugs of abuse: different effects in Fischer and Lewis rats. Brain Res Mol Brain Res 76: 18-24.

Westwood SC, Hanson GR (1999). Effects of stimulants of abuse on extrapyramidal and limbic neuropeptide Y systems. J Pharmacol Exp Ther 288: 1160-1166.

Zetterstrom RH, Williams R, Perlmann T, Olson L (1996). Cellular expression of the immediate early transcription factors Nurr1 and NGFI-B suggests a gene regulatory role in several brain regions including the nigrostriatal dopamine system. Brain Res Mol Brain Res 41: 111-120.

Supplementary Information accompanies the paper on the Neuropsychopharmacology website (http://www.nature.com/npp) 